\title{
Diagnosis of Constipation in Children
}

\author{
Frédérique Sauvat \\ Department of Pediatric Surgery, UFR Necker-Enfants Malades, University René Descartes Paris V, Paris, France
}

\section{Key Words}

Constipation · Hirschsprung's disease $\cdot$ Pediatrics

\begin{abstract}
Constipation is a frequent reason for consulting a pediatrician. As a symptom, constipation can be due to various etiologies in terms of frequency, nature and seriousness. Constipation may be of medical or surgical origin or idiopathic. Surgical etiologies are mainly represented by Hirschsprung's disease. It is the main differential diagnosis even if it is $\mathbf{5 0}$ times less frequent than idiopathic or functional constipation. A thorough history and physical examination, including anal examination, are the best way to reach a diagnosis. No other examination is required in most of the cases and all investigations have to be managed according to clinical considerations.

Copyright $\odot 2007$ Nestec Ltd., Vevey/S. Karger AG, Basel
\end{abstract}

Constipation is the reason for consulting a pediatrician in $3 \%$ of the cases and a gastroenterologist in more than $25 \%[1,2]$. The first difficulty with regard to constipation is to define the normal number of stools a child should have. Indeed this varies according to age and the type of food. Constipation can be defined by a frequency of spontaneous stools of less than 3/week. It can be accompanied by other signs (abdominal pains) that are

\begin{tabular}{ll}
\hline KARGER & $\begin{array}{l}\text { (c) } 2007 \text { Nestec Ltd., Vevey/S. Karger AG, Basel } \\
0517-8606 / 07 / 0652-0063 \$ 23.50 / 0\end{array}$ \\
$\begin{array}{l}\text { Fax }+41613061234 \\
\text { E-Mail karger@karger.ch } \\
\text { www.karger.com }\end{array}$ & $\begin{array}{l}\text { Accessible online at: } \\
\text { www.karger.com/ane }\end{array}$
\end{tabular}

more or less incapacitating and have an effect on social and school life [3]. As a symptom, constipation could cover various etiologies in terms of frequency, nature and seriousness [4]. These etiologies can be divided into medical and surgical causes; constipation most often being idiopathic or functional [5].

\section{Idiopathic Constipation}

This is by far the first etiology of constipation [6]. As children age, normal physiological changes occur in the intestines and colon that decrease the daily number of stools from a mean of 2.2 in infants younger than 1 year of age to a mean of 1.4 in 1-year-old children [7]. Constipation can be defined as less than 1 stool/day during the first months of life and 3/week in the older child. The peak of frequency for constipation corresponds to the age at which the child was toilet trained (2-4 years), with a higher prevalence in boys. The diagnosis of functional constipation can be based on the criteria of Rome, according to the age of the patient $[2,8]$.

Diagnosis is confirmed when at least two of the following symptoms persist for at least one month: (1) 2 stools or less per week; (2) at least one episode of incontinence per week; (3) history of stool-withholding behavior; (4) abdominal pain; (5) fecaloma in the rectum, and (6) existence of bulky stools able to clog toilets. 
Approximately $40 \%$ of the children suffering from functional constipation develop symptoms during the first year of life. It is also thought that in children under 4 years of age, the prognosis is better if treatment is instituted before 2 years of age. Episodes of incontinence exist in $84 \%$ of the patients [9]. In typical cases, no complementary assessment is necessary, and a plain abdominal $\mathrm{X}$-ray is sufficient to evaluate stool retention if clinical examination is difficult (obesity) [10]. It is necessary to confirm the absence of vertebral or medullar anomalies (see below). In the same way, an anorectal digital examination must be carried out to eliminate a minimal anorectal malformation, to examine the tonicity of the anal sphincter, and the presence of a fecaloma [11]. Treatment rests on an as complete as possible evacuation of the colon, softening of stool consistency, and modification of dietary intake and life habits. Dietetic errors (dehydration, diet low in residues, etc.) as well as local causes can maintain constipation while making the expulsion of stools difficult or painful.

\section{Medical Causes of Constipation}

In rarer cases, childhood constipation is caused by an endocrine dysfunction or a metabolic or toxic cause.

Hypothyroidism is the principal endocrine cause of constipation. However, systematic screening in the neonatal period (Guthrie test) allows early diagnosis, thereby reducing the neurological consequences of a later diagnosis. Diabetes [12] and hypoparathyroidism have also been described as causes of constipation, but transit disorders are seldom the first sign.

Electrolyte imbalances can slow down bowel motions, as is the case with hypo- and hypercalcemia $[13,14]$.

The possibility of poisoning must always be considered when taking down the medical history, without forgetting any treatment taken by a nursing mother. The main treatments responsible for constipation during infancy are: anticholinergics, antispasmodics, and certain resins (cholestyramine). The addition of a thickener ( $\mathrm{Gu}-$ milk ${ }^{\circledR}$ ) to the infant's formula should not be forgotten as this can be the origin of constipation, even of a true occlusive syndrome, due to the accumulation of compact stools, particularly in the cecum.

As already stated, inappropriate diet can induce constipation. The principal etiologies are: (1) malnutrition, anorexia; (2) dehydration [15]; (3) an excess of cow's milk [16], and (4) residue insufficiency, particularly in the larger child.
Celiac disease [17] (gluten intolerance) can be accompanied by episodes of constipation.

Cystic fibrosis can be accompanied by constipation in the neonatal period (meconium ileus), or later during infancy, due to exocrine pancreatic insufficiency. During the prenatal period, cystic fibrosis can be suspected when an occlusive syndrome is associated with digestive hyperechogenicity (and lead to prenatal diagnosis by amniocentesis). At birth, meconium ileus is an occlusion of the ileum with delayed elimination of meconium and abdominal distension. The radiographic aspect is typical when there are opacities in the right abdomen. Rectal injection with gastrograffin shows a nonfunctional colon, a typical aspect in the cecum and the ileum where the product forms small balls of meconium. In case of intervention, which should be avoided by all means, the pasty macroscopic aspect of meconium is characteristic. Immunoreactive trypsin and molecular biology confirm the diagnosis. As for hypothyroidism, screening is now obligatory in France in the neonatal period.

\section{Surgical Causes of Constipation}

The principal organic cause of constipation is Hirschsprung's disease (HD). But it should not be forgotten that HD is 50 times less frequent than idiopathic constipation.

\section{Hirschsprung's Disease}

$\mathrm{HD}$, or congenital megacolon, is a congenital malformation characterized by the lack of enteric ganglionic cells on a variable length of the intestine. Whatever the length of the affected region, intestinal intrinsic innervation always starts above the anal region and extends more or less up to the colon or even the small bowel. In $75-80 \%$ of the cases, HD affects the rectum and sigmoid [18]. The total colonic form is found in $10 \%$ of all cases, and total intestinal aganglionosis (including the jejunum) in less than $1 \%$. The abnormality is due to the absence of ganglionic cells in the myenteric and submucous plexus of Meissner and Auerbach, and associated with hypertrophy of amyelinic fibers. This aganglionosis is responsible for the hypertonicity of the pathological intestine.

\section{Epidemiology of HD}

The frequency of $\mathrm{HD}$ in the general population is $1 \mathrm{in}$ 5,000 births [19]. It is predominantly seen in boys: $4 / 1$ in the short form (rectosigmoid). The risk of recurrence for 
first-degree relatives is low (4\%) but significantly increases when the index case is female or has an extended form. Most cases are sporadic; the familial form represents 6$15 \%$ of cases with a dominant autosomal transmission and incomplete penetrance [20-22].

\section{Clinical Presentation}

Symptoms vary according to age and extent of disease. In all cases, it is a functional obstruction.

\section{Neonatal Diagnosis without Complicated HD [23,} 24]

The possibility of HD is systematically suspected in neonates with functional obstruction, especially if the baby is full term with a normal prenatal ultrasound.

The usual clinical signs are: (1) delay in meconial emission, after $24-48 \mathrm{~h}$; (2) progressively increasing abdominal distension in the 2 first days of life, and (3) alimentary vomiting, bilious vomiting is often delayed.

The best clinical sign for a positive diagnosis of HD is the sudden discharge of gas and meconium after anorectal digital examination or installation of a rectal tube. In the rectosigmoid form, the rectal tube, placed above the aganglionic part, allows evacuation of withheld stools, and a rapid decrease in abdominal distension [25]. The tube must be placed after X-ray (no pneumoperitoneum) and care must be taken to avoid perforation, especially if enterocolitis is suspected. Lack of sudden discharge does not exclude the diagnosis in case of a long form. Diagnosis of $\mathrm{HD}$ is made in the majority of cases during the first trimester [26].

\section{Diagnosis of HD in Infants}

The possibility of HD in neonates with constipation must be suspected, especially if the motility disorder appeared or increased after weaning and food diversification, when stools become compact. Stool frequency is variable, sometimes with no defecation over several days. The abdomen is chronically distended, but less so after stimulation (laxative, etc.). Rectal examination eliminates lower anorectal malformations (in situ anal stenosis) and helps to detect upper fecal impaction. Growth is usually poor.

\section{Later Diagnosis}

In nearly all cases, short forms of HD can be diagnosed. Children have a long history of obstinate constipation with recurrent episodes of sub-occlusion, with distension of the whole abdominal wall. Constipation is known from birth, with stimulated bowel movements only every several days. Often dried out stools are mixed with liquid and foul stools caused by chronic retention. An important clinical point is that continence is always normal in $\mathrm{HD}$; encopresis is never associated with $\mathrm{HD}$. In some cases, HD has an important impact on growth and long-term psychological development [27].

\section{Extended HD [28, 29]}

The diagnosis of the long form of HD is often difficult and delayed [30]. The clinical picture may be very variable: (1) intestinal (ileal) neonatal occlusion, sometimes incomplete with or without spontaneous evacuation of meconium, and clinical signs, such as X-ray, could help to diagnose meconium ileus; (2) neonatal enterocolitis $[31,32]$ could be related to extended HD in the absence of prematurity or severe cardiopathy; (3) acute presentation with appendicular or cecal perforation [33], and (4) severe constipation in neonates, particularly due to bad tolerance with a major effect on growth.

\section{Complicated HD}

The two main complications of HD are gut perforation and enterocolitis. These complications can reveal HD or occur during the course of the disease and can be life-threatening.

Enterocolitis [34] can be considered as septicemia of intestinal origin, secondary to endoluminal microbial proliferation induced by stasis associated with ulceration of the intestinal wall and ischemia by distension. Clinically, the child presents with a major painful abdominal distension and deep sepsis. Stools are liquid and foul smelling or bloody. X-ray shows global dilatation, but pneumatosis is scarce. Treatment of enterocolitis in HD is associated with broad-spectrum antibiotic therapy (focusing on Gram-negative and anaerobic germs) and surgical diversion (in a normally innervated zone).

Perforation can occur in a normally innervated zone [35]. Emergency surgery is necessary for a pneumoperitoneum. A positive diagnosis of HD could be difficult because caliber disparity may be lacking. In such a situation the diagnosis should be kept in mind and lead to a rectal biopsy in association with stoma above the perforation [36].

\section{Diagnosis of HD}

The diagnosis of HD is based on colonic opacification, but mostly on a rectal biopsy, which is the only way to make a clear diagnosis in the absence of ganglionic cells. 

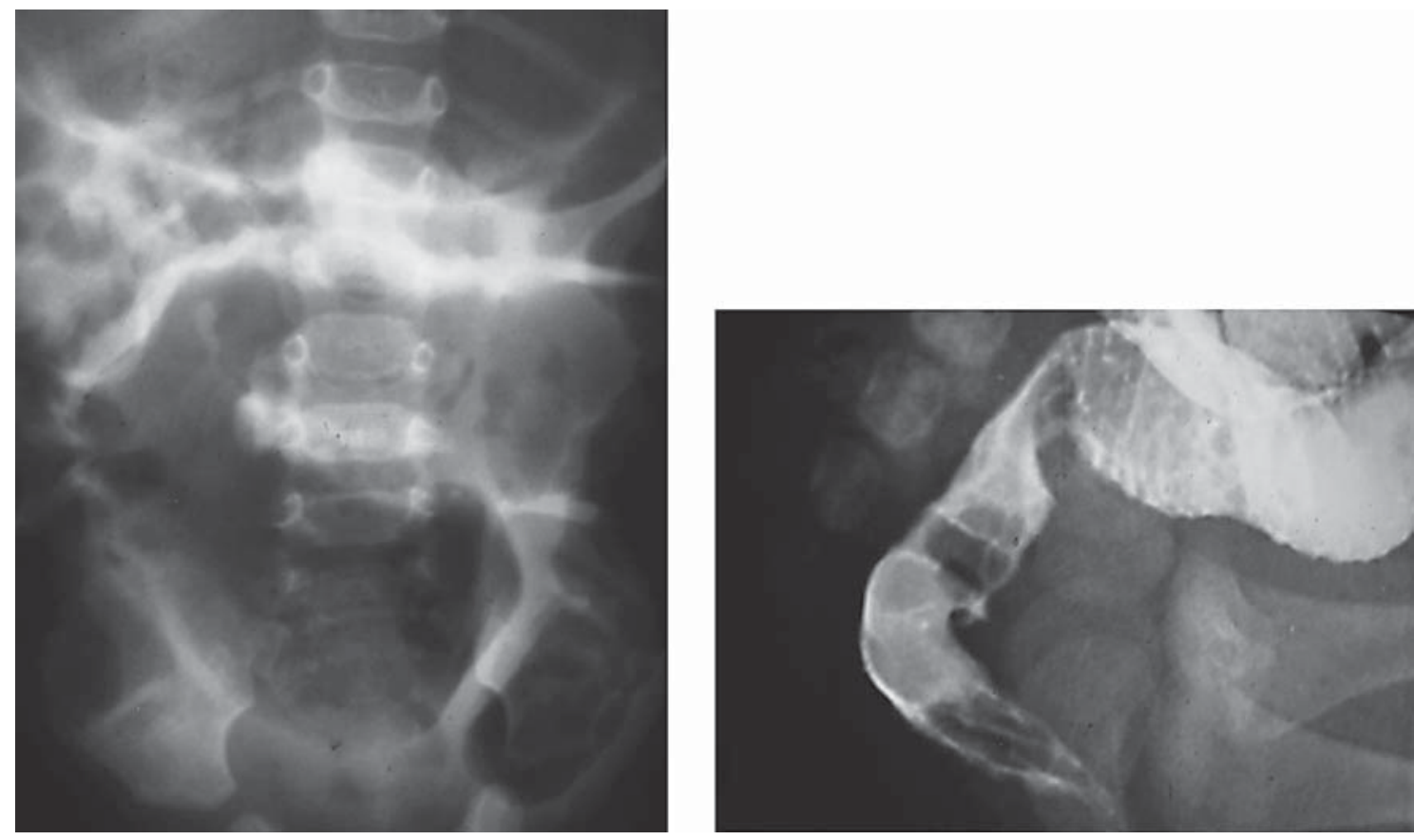

Fig. 1. Typical aspect of rectosigmoidal Hirschsprung disease on X-ray and baryum opacification.

\section{Radiological Opacification [37, 38]}

The aim of colonic opacification is to show the diameter disparity between the narrowed aganglionic part and the dilated normal segment. Furthermore, it allows estimation of the length of the diseased colon. In neonates this examination is often difficult to interpret.

It must be performed under good conditions and in the absence of pneumoperitoneum and enterocolitis. Contrast progression (preferentially barium) is monitored using a scope, with face and profile incidence, focusing on the disparity in diameter. Often the best films are the plane ones (and after $1 \mathrm{~h}$ ).

In the rectosigmoid form, the rectal part has a normal aspect, followed by a transitional part widening up to the dilated normal colon. This disparity in caliber is specific of HD (fig. 1).

In the total colonic form, opacification could have different aspects [39]: (1) a short colon shaped like a question mark, with disappearance of the right and left colonic corners (fig. 2); (2) a microcolon associated with more or less marked dilatation of the ileum - in this form the differential diagnosis is meconium ileus or microcolon megabladder syndrome, and (3) a normal aspect (30\%).

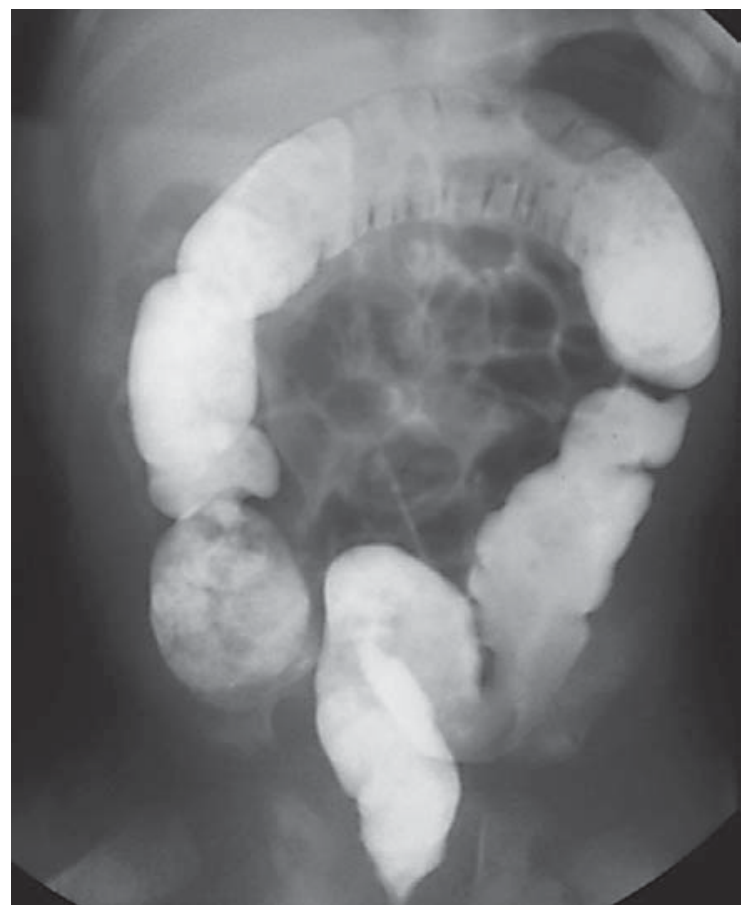

Fig. 2. Radiological opacification in colonic form of HD. 
Anorectal Manometry [40, 41]

Using manometry, the lack of a rectoanal inhibiting reflex is the main sign for a diagnosis of HD. But the presence of a false-positive reflex makes a rectal biopsy essential. Usually it is thought that manometry has little value in neonates (before 3 months of life).

\section{Rectal Biopsy}

Histological examination enables a definite diagnosis and is therefore crucial. Rectal biopsy must be made at least $3 \mathrm{~cm}$ above the anal margin to avoid a false-positive result (a biopsy made too low could be situated in a normal hypoganglionic part). This biopsy can be performed in two ways.

(1) Rectal suction biopsy (with H. Noblett grasp) is realized without anesthesia. Usually, two pieces are removed 3 and $6 \mathrm{~cm}$ from the anal margin. The limits of the technique are that a trained pathologist is needed and the biopsy must contain muscularis mucosa and, if possible, submucosa.

(2) Surgical biopsy should contain the whole rectal wall (Swenson technique). It requires general anesthesia but allows a deeper and more contributory biopsy.

Histological results supporting the diagnosis of $\mathrm{HD}$ are [42]: (1) on fixed pieces and standard histology, the lack of ganglionic cells and hypertrophy of amyelinic fibers (often missing in neonates) [43], and (2) by immunohistochemistry (frozen pieces) hyperplasia of cholinergic fiber is seen in the submucosal and muscular parts, together with nervous fiber climbing in the mucosa.

\section{Treatment}

The treatment of HD is surgical and consists of removing the aganglionic zone and anastomosis between the anus and normal innervated bowel [44]. In the preoperative period stools must be evacuated either by rectal evacuation or stoma.

\section{Preoperative Management}

Rectal evacuation is useful to evacuate stools through a rectal tube pushed above the aganglionic colon. The tube must be placed one to three times a day, allowing a decrease in abdominal distension and correction of the growth curve. This simple approach can be considered only in the short form of HD. It enables the patient to return home to await surgery, if the family is able to perform the management and are able to decide whether rectal evacuation is inefficient or the abdomen distended.

\section{Stoma}

The rule is that stoma should be performed in a normally innervated bowel and as distally as possible, avoiding the transition part. The stoma will be pulled through during final surgery. The indications for stoma at the time of diagnosis are: the long form; the short form with inefficient rectal evacuation, and the complicated form (enterocolitis).

During surgery, collaboration with a pathologist confirms that the stoma has been well placed. In the long form, biopsies should be numerous, including the appendix, and ileostomy is often necessary.

\section{Enteroanal Pull-Through}

Three common techniques have been described by Swenson, Duhamel and Soave, respectively. These approaches can be used with equivalent short- and longterm results whatever the form and length of disease. The surgical innovations include the use of laparoscopy for biopsy or intra-abdominal dissection and pull-through by the transanal approach.

Whatever the technique, it is important to focus on: (1) preoperative preparation of the colon; (2) perfect histological analysis during surgery to avoid pull-through in the transition part, and (3) antibiotic prophylaxis.

Some complications appear soon after surgery: (1) Fistula on the anastomosis revealed by pelvic abscess, requiring antibiotics and often a stoma. (2) Stenosis of the anastomosis is frequent and usually benign, with good responses after dilatation [45]. (3) Enterocolitis remains a more serious complication, and could occur up to 2 years after surgery [46]. As previously described, clinical signs are abdominal distension, diarrhea and alterations in the general status. (4) Skin erosion around the anus is seen in nearly every case and responds variably to local treatment. (5) Defecation disorders can be seen in the longterm follow-up even without surgical complications [47].

\section{Surgical Techniques}

Duhamel Pull-Through. This technique was described in 1956 and is based on rectal conservation using a retrorectal pull-through of the normal innervated bowel. It remains interesting due to its surgical simplicity and the limited dissection of the structures (pelvic nerves) around the rectum. Anastomosis can be realized at the same time, using automatic staples such as GIA. The main complication of the Duhamel procedure is a colorectal spur responsible for fecaloma $[48,49]$.

Swenson Pull-Through. Described in 1948, this operation includes complete resection of the aganglionic seg- 


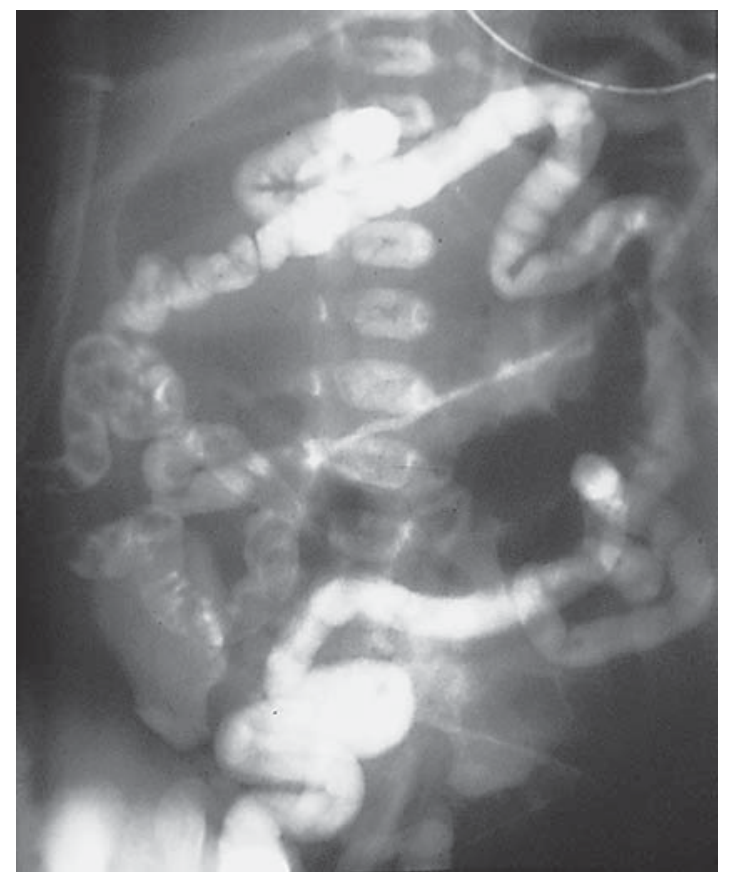

Fig. 3. Typical aspect of meconial ileux in cystic fibrosis, at birth.

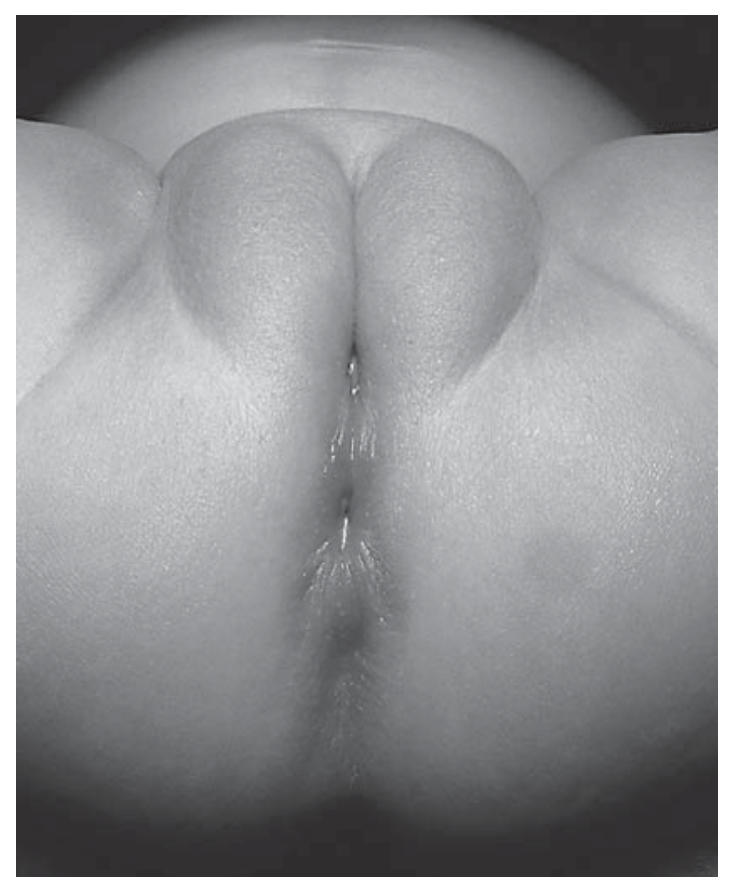

Fig. 5. Low anorectal malformation in a girl (anus in vulvar position).

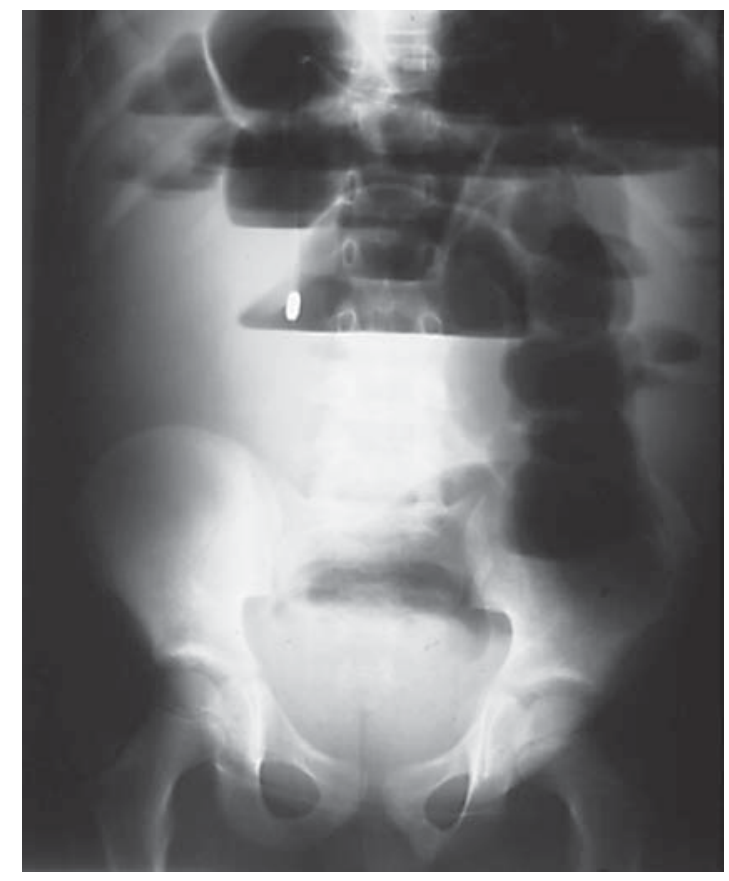

Fig. 4. Small bowel dilatation in CIPOS.

ment and anal anastomosis. The two main complications are neurological bladder impairment (pelvic nerve injury) and stenosis of the anastomosis.

Soave Pull-Through. Described in 1963, the principle is a colonic pull-through in a muscular rectal cylinder. The advantage is the lack of pelvic dissection, but the complication remains constipation when the cylinder is too long.

Transanal Pull-Through [50]. The principle is the realization of a Soave technique without laparotomy. It is especially interesting in neonates, but must be reserved for the short form [51].

Laparoscopy. Laparoscopy can be used to take biopsies or for dissection during the Duhamel or Swenson procedures.

\section{Other Functional Obstructions}

When confronted with abdominal distension in a newborn baby with delayed meconium emission, other causes of organic or functional obstruction must be eliminated: anal imperforation; colonic or ileal atresia (occasionally seen with Morgagni's hernia); meconium ileus (associated with cystic fibrosis; fig. 3); small left colon syndrome, or a meconium plug [52]. 
Small left colon syndrome and the meconium plug are characterized by the small diameter of the rectosigmoid and the left colon up to the left angle and the sigmoid or iliac colon. During opacification, a plug is eliminated following a rectal injection (the head of this mould is often grayish and the rest of the meconium is normal). Transit is then strictly normal. However, it is necessary to reexamine these children during the first months of life, and to carry out a rectal biopsy to rule out any doubt of HD [53].

\section{Chronic Intestinal Pseudo-Obstruction}

The chronic intestinal pseudo-obstruction syndrome (CIPOS) is a very uncommon etiology of constipation. This diagnosis could be discussed in severe cases of constipation and failure of medical treatment.

CIPOS is characterized by repetitive episodes or continuous symptoms and signs of bowel obstruction, including radiographic documentation of dilated bowel (fig. 4), in the absence of a fixed lumen-occluding lesion [54].

Regardless of the histologic type (myogenic or neurogenic) [55], CIPOS always involves alterations in smooth muscle contractile function, leading to abnormal intestinal tract peristalsis and finally nutritional disorders from both intestinal failure and recurrent sepsis. The accompanying uropathies must be sought in all patients with CIPOS. The clinical impact of these uropathies (megabladder, renal dilatation, etc.) may be important, sometimes requiring vesicostomy. This association explains the necessity of urologic ultrasound when the etiologic diagnosis of constipation is difficult. In the same way, rectal biopsy and anorectal manometry could be required to show the presence of ganglionic cells and rectoanal reflex.

\section{Anorectal Malformations}

Anal examination is essential in the newborn at birth to ascertain rectal permeability. Especially in girls (fig. 5), anorectal malformations with perineal fistula could be missed during several months or years even though the diagnosis is clinical. The anus is near the vulvar or scrotal region. The external sphincter is located behind the anal fistula. Rectoanal digital examination is impossible, even with 5th finger.

As already explained, at least one well-conducted anal examination is always required for the diagnosis of constipation.

Constipation is also frequent after treatment of anorectal malformations [56]. Risk increases in cases with a high anorectal form, associated with sacral and medullar abnormalities [57]. For example, continence is considered as socially normal in $75-85 \%$ with low malformations and in only $50 \%$ after treatment of high anorectal malformations. Management of constipation in these patients is specific, it is associated with medical treatment, perineal reeducation and in some cases surgery (cecostomy [58] to carry out anterograde washout).

\section{Medullar and Sacral Malformations}

Constipation could have neurological origins after medullar injury (traumatism, tumors, infections, etc.) [59] but diagnosis in these cases raises a few problems.

Isolated abnormalities of the sacrum or filum terminale may be revealed by constipation. Examination has to focus on the sacral region (dimple, lipoma, angioma, etc.). Once the abdominal X-rays have been taken, the sacrum must be studied, and ultrasound in neonates or MRI must complete the radiological examinations.

For example, Currarino syndrome is associated with a presacral tumor (usually teratoma), sacral abnormalities (cemetery sacrum) and anorectal malformations (from a nearly normal anus to higher anorectal malformations) [60]. The first clinical signs could be constipation or urinary difficulties.

In conclusion, constipation is a common reason for consultation during childhood, and the etiologies are very variable. But careful evaluation of medical history and physical examination are the best way to come to a diagnosis. No other examination is required and all investigations must be managed according to the clinical considerations. 


\section{References}

1 Constipation Guideline Committee of the North American Society for Pediatric Gastroenterology, Hepatology and Nutrition: Evaluation and treatment of constipation in infants and children: recommendations of the North American Society for Pediatric Gastroenterology, Hepatology and Nutrition. J Pediatr Gastroenterol Nutr 2006;43: e1-e13.

-2 van den Berg MM, Benninga MA, Di Lorenzo C: Epidemiology of childhood constipation: a systematic review. Am J Gastroenterol 2006;101:2401-2409.

-3 Khan S, Campo J, Bridge JA, et al: Long-term outcome of functional childhood constipation. Dig Dis Sci 2007;52:64-69.

-4 Singh SJ, Arbuckle S, Little D, et al: Mortality due to constipation and short-segment Hirschsprung's disease. Pediatr Surg Int 2004;20:889-891.

5 Nurko S: What's the value of diagnostic tools in defecation disorders? J Pediatr Gastroenterol Nutr 2005;41(suppl 1):S53-S55.

-6 Drost J, Harris LA: Diagnosis and management of chronic constipation. JAAPA 2006; 19:24-29.

7 Biggs WS, Dery WH: Evaluation and treatment of constipation in infants and children. Am Fam Physician 2006;73:469-477.

$\checkmark 8$ Drossman DA, Dumitrascu DL: Rome III: New standard for functional gastrointestinal disorders. J Gastrointestin Liver Dis 2006; 15:237-241.

-9 Rubin G, Dale A: Chronic constipation in children. BMJ 2006;333:1051-1055.

10 Remes-Troche JM, Rao SS: Diagnostic testing in patients with chronic constipation. Curr Gastroenterol Rep 2006;8:416-424

-11 Safder S, Rewalt M, Elitsur Y: Digital rectal examination and the primary care physicians: a lost art? Clin Pediatr 2006;45:411414.

-12 Narbonne H, Paquis-Fluckinger V, Valero R, et al: Gastrointestinal tract symptoms in Maternally Inherited Diabetes and Deafness (MIDD). Diabetes Metab 2004;30:61-66.

$\checkmark 13$ Barrueto F Jr, Wang-Flores HH, Howland MA, et al: Acute vitamin D intoxication in a child. Pediatrics 2005; 116:e453-e456

14 Wu MJ, Chang CS, Cheng CH, et al: Colonic transit time in long-term dialysis patients. Am J Kidney Dis 2004;44:322-327.

15 Manz F, Wentz A: The importance of good hydration for the prevention of chronic diseases. Nutr Rev 2005;63:S2-S5.

16 Kawai M, Kubota A, Ida S, et al: Cow's milk allergy presenting Hirschsprung's diseasemimicking symptoms. Pediatr Surg Int 2005 21:850-852

17 Rashid M, Cranney A, Zarkadas M, et al: Celiac disease: evaluation of the diagnosis and dietary compliance in Canadian children. Pediatrics 2005; 116:e754-e759.
18 Kessmann J: Hirschsprung's disease: diag nosis and management. Am Fam Physician 2006;74:1319-1322.

19 Attie T, Salomon R, Amiel J, et al: Genetics of Hirschsprung disease (in French). CR Seances Soc Biol Fil 1996;190:549-556.

20 Lyonnet S, Bolino A, Pelet A, et al: A gene for Hirschsprung disease maps to the proximal long arm of chromosome 10. Nat Genet 1993; 4:346-350.

21 Blok S, Salomon R, Pelet A, et al: Segregation of three loci explains familial and population risks in Hirschsprung disease. Nat Genet 2002;31:89-93.

22 Amiel J, Lyonnet S: Hirschsprung disease, associated syndromes, and genetics: a review. J Med Genet 2001;38:729-739.

23 Swenson O: Hirschsprung's disease: a review. Pediatrics 2002;109:914-918.

24 Reding R, de Ville de Goyet J, Gosseye S, et al: Hirschsprung's disease: a 20-year experience. J Pediatr Surg 1997;32:1221-1225.

-25 Polley TZ Jr, Coran AG, Wesley JR: A tenyear experience with ninety-two cases of Hirschsprung's disease. Including sixty-seven consecutive endorectal pull-through procedures. Ann Surg 1985;202:349-355.

26 Coran AG, Teitelbaum DH: Recent advances in the management of Hirschsprung's disease. Am J Surg 2000;180:382-387.

27 Stam H, Hartman EE, Deurloo JA, et al: Young adult patients with a history of pediatric disease: impact on course of life and transition into adulthood. J Adolesc Health 2006;39:4-13.

28 Tsuji H, Spitz L, Kiely EM, et al: Management and long-term follow-up of infants with total colonic aganglionosis. J Pediatr Surg 1999; 34:158-162.

29 Jasonni V, Martucciello G: Total colonic aganglionosis. Semin Pediatr Surg 1998;7: 174-180.

30 Escobar MA, Grosfeld JL, West KW, et al: Long-term outcomes in total colonic aganglionosis: a 32-year experience. J Pediatr Surg 2005;40:955-961.

31 Elhalaby EA, Teitelbaum DH, Coran AG, Heidelberger KP: Enterocolitis associated with Hirschsprung's disease: a clinical histopathological correlative study. J Pediatr Surg 1995;30:1023-1027.

-32 Elhalaby EA, Coran AG, Blane CE, et al: Enterocolitis associated with Hirschsprung's disease: a clinical-radiological characterization based on 168 patients. J Pediatr Surg 1995;30:76-83.

33 Sarioglu A, Tanyel FC, Buyukpamukcu N, Hicsonmez A: Appendiceal perforation: a potentially lethal initial mode of presentation of Hirschsprung's disease. J Pediatr Surg 1997;32:123-124.

34 Teitelbaum DH, Coran AG: Enterocolitis. Semin Pediatr Surg 1998;7:162-169.
35 Courvoisier S, Piolat C, Durand C, et al: Pseudo-'isolated' intestinal perforation in a very low birth weight infant: exceptional presentation of Hirschsprung's disease (in French). Arch Pediatr 2006;13:1320-1322.

-36 Arliss J, Holgersen LO: Neonatal appendiceal perforation and Hirschsprung's disease. J Pediatr Surg 1990;25:694-695.

37 Faure F, Panuel M, Petit PH, et al: Methodes d'explorations radiologiques de l'ano-rectum; in Le rectum pédiatrique. Monographie du college national de chirurgie pédiatrique. Montpellier, Sauramps Médical, 1996, pp 43-49.

38 Fotter R: Imaging of constipation in infants and children. Eur Radiol 1998;8:248-258.

-39 Fondelli P, Martucciello G, Taccone A, Dodero P: The radiologic picture of total colonic aganglionosis (in Italian). Radiol Med (Torino) 1989;77:207-210.

40 Fink RL, Roberts LJ, Scott M: The role of manometry, electromyography and radiology in the assessment of intractable constipation. Aust NZ J Surg 1992;62:959-964.

41 Meunier P, Marechal JM, Mollard P: Accuracy of the manometric diagnosis of Hirschsprung's disease. J Pediatr Surg 1978; 13:411-415.

42 Kapur RP: Can we stop looking? Immunohistochemistry and the diagnosis of Hirschsprung disease. Am J Clin Pathol 2006;126:9-12

43 Matsuda H, Hirato J, Kuroiwa M, Nakazato Y: Histopathological and immunohistochemical study of the enteric innervations among various types of aganglionoses including isolated and syndromic Hirschsprung disease. Neuropathology 2006;26: 8-23.

44 Hartman EE, Sprangers MA, Visser MR, et al: Hirschsprung's disease: healthcare meets the needs. J Pediatr Surg 2006;41:14201424.

45 Catto-Smith AG, Trajanovska M, Taylor RG: Long-term continence in patients with Hirschsprung's disease and Down syndrome. J Gastroenterol Hepatol 2006;21: 748-753.

46 Menezes M, Puri P: Long-term outcome of patients with enterocolitis complicating Hirschsprung's disease. Pediatr Surg Int 2006;22:316-318.

47 Hyman PE: Defecation disorders after surgery for Hirschsprung's disease. J Pediatr Gastroenterol Nutr 2005;41(suppl 1):S62S63.

48 Saleh W, Rasheed K, Mohaidly MA, et al: Management of Hirschsprung's disease: a comparison of Soave's and Duhamel's pullthrough methods. Pediatr Surg Int 2004;20: 590-593. 
49 Minford JL, Ram A, Turnock RR, et al: Comparison of functional outcomes of Duhamel and transanal endorectal coloanal anastomosis for Hirschsprung's disease. J Pediatr Surg 2004;39:161-165.

50 Dasgupta R, Langer JC: Transanal pullthrough for Hirschsprung disease. Semin Pediatr Surg 2005;14:64-71.

-51 Podevin G, Lardy H, Azzis O, et al: Technical problems and complications of a transanal pull-through for Hirschsprung's disease. Eur J Pediatr Surg 2006;16:104-108.

52 Yamauchi K, Kubota A, Usui N, et al: Benign transient non-organic ileus of neonates. Eur J Pediatr Surg 2002;12:168-174.
53 Cowles RA, Berdon WE, Holt PD, et al: Neonatal intestinal obstruction simulating meconium ileus in infants with long-segment intestinal aganglionosis: radiographic findings that prompt the need for rectal biopsy. Pediatr Radiol 2006;36:133-137.

54 Joly F, Amiot A, Coffin B, et al: Chronic intestinal pseudo-obstruction (in French). Gastroenterol Clin Biol 2006;30:975-985.

55 Meier-Ruge WA, Bruder E: Pathology of chronic constipation in pediatric and adult coloproctology. Pathobiology 2005;72:1-102. 6 Hartman EE, Oort FJ, Aronson DC, et al: Critical factors affecting quality of life of adult patients with anorectal malformations or Hirschsprung's disease. Am J Gastroenterol 2004;99:907-913.

57 Hamid CH, Holland AJ, Martin HC: Longterm outcome of anorectal malformations: the patient perspective. Pediatr Surg Int 2006; Epub ahead of print.
58 Yagmurlu A, Harmon CM, Georgeson KE: Laparoscopic cecostomy button placement for the management of fecal incontinence in children with Hirschsprung's disease and anorectal anomalies. Surg Endosc 2006;20: 624-627.

59 Valles M, Vidal J, Clave P, Mearin F: Bowel dysfunction in patients with motor complete spinal cord injury: clinical, neurological, and pathophysiological associations. Am J Gastroenterol 2006;101:2290-2299.

60 Kilickesmez O, Gol IH, Uzun M, Oruk C: Complete familial Currarino triad in association with Hirschsprung's disease: magnetic resonance imaging features and the spectrum of anorectal malformations. Acta Radiol 2006;47:422-426. 